\title{
Aspirated bile: a major host trigger modulating respiratory pathogen colonisation in cystic fibrosis patients
}

\author{
F. J. Reen • D. F. Woods • M. J. Mooij • M. N. Chróinín • \\ D. Mullane $\cdot$ L. Zhou $\cdot$ J. Quille $\cdot$ D. Fitzpatrick $\cdot$ \\ J. D. Glennon • G. P. McGlacken • C. Adams • F. O'Gara
}

Received: 10 January 2014 / Accepted: 21 April 2014 /Published online: 11 May 2014

(C) The Author(s) 2014. This article is published with open access at Springerlink.com

\begin{abstract}
Chronic respiratory infections are a leading global cause of morbidity and mortality. However, the molecular triggers that cause respiratory pathogens to adopt persistent and often untreatable lifestyles during infection remain largely uncharacterised. Recently, bile aspiration caused by gastrooesophageal reflux (GOR) has emerged as a significant complication associated with respiratory disease, and cystic fibrosis (CF) in particular. Based on our previous finding that the physiological concentrations of bile influence respiratory pathogens towards a chronic lifestyle in vitro, we investigated the impact of bile aspiration on the lung microbiome of respiratory patients. Sputum samples $(n=25)$ obtained from a cohort of paediatric CF patients were profiled for the presence of bile acids using high-resolution liquid
\end{abstract}

Electronic supplementary material The online version of this article (doi:10.1007/s10096-014-2133-8) contains supplementary material, which is available to authorized users.

F. J. Reen · D. F. Woods · M. J. Mooij · C. Adams · F. O'Gara $(\bowtie)$ BIOMERIT Research Centre, School of Microbiology, University College Cork-National University of Ireland, Cork, Ireland e-mail: f.ogara@ucc.ie

M. N. Chróinín · D. Mullane

Paediatric Cystic Fibrosis Clinic, Cork University Hospital, Cork, Ireland

L. Zhou · J. Quille · D. Fitzpatrick · J. D. Glennon - G. P. McGlacken School of Chemistry and Analytical and Biological Chemistry Research Facility (ABCRF), University College Cork-National University of Ireland, Cork, Ireland

F. O'Gara

School of Biomedical Sciences, Curtin University, Perth, WA 6845 , Australia

Present Address:

M. J. Mooij

Department of Medical Microbiology, Maastricht University

Medical Centre, 6202 AZ Maastricht, The Netherlands chromatography-mass spectrometry (LC-MS). Pyrosequencing was performed on a set of ten DNA samples that were isolated from bile aspirating $(n=5)$ and non-bile aspirating $(n=5)$ patients. Both denaturing gradient gel electrophoresis (DGGE) and pyrosequencing revealed significantly reduced biodiversity and richness in the sputum samples from bile aspirating patients when compared with non-aspirating patients. Families and genera associated with the pervasive $\mathrm{CF}$ microbiome dominated aspirating patients, while bacteria associated with the healthy lung were most abundant in nonaspirating patients. Bile aspiration linked to GOR is emerging as a major host trigger of chronic bacterial infections. The markedly reduced biodiversity and increased colonisation by dominant proteobacterial $\mathrm{CF}$-associated pathogens observed in the sputum of bile aspirating patients suggest that bile may play a major role in disease progression in $\mathrm{CF}$ and other respiratory diseases.

\section{Introduction}

Chronic respiratory infections associated with lung disease are a major cause of global morbidity and mortality (http://who.int/mediacentre/factsheets/fs310/en/). Despite concerted global research efforts, little progress has been made in the clinical management of these chronic infections. Current treatment strategies remain extremely limited, particularly where chronic pathogens adopt a biofilm lifestyle. Recent clinical investigations have highlighted bile aspiration into the lungs as a major consequence of gastrooesopheageal reflux (GOR) [1-4]. GOR is routinely detected in respiratory patients, with incidences as high as $40-80 \%$ reported for cystic fibrosis $(\mathrm{CF})$ patients $[4,5]$. GOR in $\mathrm{CF}$ patients is associated with reduced lung function manifesting as reduced forced expiratory volume (FEV) and forced vital capacity $(\mathrm{FVC})[6,7]$. However, to date, the mechanism by 
which bile aspiration contributes to reduced pulmonary function remains unknown. Recently, we have shown that physiologically relevant concentrations of bile cause Pseudomonas aeruginosa and other respiratory pathogens to adopt a chronic biofilm lifestyle in vitro [8]. Furthermore, we have also demonstrated that bile acids modulate molecular targets in the host, suppressing the master regulator of the host hypoxic and immune response, HIF-1 (Legendre, C., Mooij, M., Adams, C. et al., manuscript in revision). This strongly suggests that bile aspiration into the lungs may be a major host determinant that triggers the establishment of dominant chronic biofilm-forming microbial species.

Several recent reports have highlighted the existence of a $\mathrm{CF}$ microbiome, with distinct microbial profiles from healthy non-CF patients [9-14]. While the factors that shape this CF microbiome remain unknown, our previous studies suggest that bile aspiration may influence the microbial diversity and, particularly, the emergence of dominant chronic pathogens in CF patients [8]. To investigate this, the bile aspiration status of patients was established using liquid chromatography-mass spectrometry (LC-MS) technology and the lung microbiome was subsequently investigated using 454 pyrosequencing. A cohort of paediatric CF patients was recruited for this study in order to gain insight into the early impact of bile aspiration on the emergence of chronic infection.

\section{Methods}

Patient cohort and ethics statement

Sputum samples $(n=25)$ were collected from paediatric patients attending the CF clinic at Cork University Hospital, Ireland, over a 6-month period (Table 1). Ethical approval was granted for sputum collection and all patients/guardians signed consent forms for acquisition and analysis outlined in this study. Sputum specimens were obtained by asking the patient to cough the specimen into a sterile universal container. Specimens were labelled with a unique study number. All sample collection was performed with the research group blinded to the patient data.

\section{Sample processing}

Sample processing was performed using a method adapted from Tagliacozzi and colleagues [15]. Briefly, sputum samples were treated with equal volumes of Sputolysin (Calbiochem) and vortexed for $30 \mathrm{~s}$ prior to centrifugation at 5,000 rpm for $15 \mathrm{~min}$. The supernatant was transferred into a sterile container and $250 \mu \mathrm{l}$ was removed for bile acid analysis. A $900 \mu \mathrm{l}$ aliquot of acetonitrile (Sigma-Aldrich) was added to each $250 \mu \mathrm{l}$ sample, which was vortexed for $1 \mathrm{~min}$ and centrifuged at $13,600 \mathrm{rpm}$ for $10 \mathrm{~min}$. A $900 \mu \mathrm{l}$ aliquot was transferred to a clean container and the sample was evaporated under nitrogen to dryness. The sample was then resuspended in $250 \mu \mathrm{l} \mathrm{MeOH}: \mathrm{H}_{2} \mathrm{O}$ (1:1) and subsequently analysed by LC-MS.

\section{LC-MS bile acid analysis}

Twelve bile acid standards were used and resuspended in methanol to a concentration of $20 \mathrm{mM}$; cholic acid (CA), chenodeoxycholic acid (CDCA), deoxycholic acid (DCA), lithocholic acid (LCA), ursodeoxycholic acid (UDCA), glycodeoxycholic acid (GDCA), taurochenodeoxycholic acid (TCDCA), taurodeoxycholic acid (TDCA), taurocholic acid (TCA), glycocholic acid (GCA) and taurolithocholic acid (TLCA) were purchased from Sigma-Aldrich (Buchs, Switzerland) and tauroursodeoxycholic acid (TUDCA) was purchased from Calbiochem (Darmstadt, Germany). The 12 stock solutions were then pooled together to a concentration of $100 \mu \mathrm{M}$ in methanol. All chemicals used were HPLC grade.

Profiling of the bile composition in the clinical samples was undertaken using a recently developed LC-MS protocol (Reen, F.J., Woods, D.F., Zhou, L. et al., manuscript in preparation). Briefly, each sputum sample was analysed for the presence of 12 principal bile acids compared to purified standard. Patients were considered bile aspirating where concentrations of greater than $1.0 \mu \mathrm{M}$ were detected. Baseline concentrations of less than $0.2 \mu \mathrm{M}$ bile acids, comparable to healthy non-CF samples, were considered non-bile aspirating. Duplicate samples were included in the analysis to ensure reproducibility and all analyses were performed blinded to the patient data (Table 1).

\section{Denaturing gradient gel electrophoresis (DGGE) analysis}

DNA extraction from the Sputolysin-treated sputum samples was achieved using the Puregene DNA isolation kit (Qiagen), according to the manufacturer's instructions. DNA was RNase-treated to remove residual RNA and quantified to $100 \mathrm{ng} / \mu \mathrm{l}$. Bacterial 16S rRNA amplification was performed using the universal primers $518 \mathrm{R}$ and F338GC, while the fungal internally transcribed region (ITS) was amplified using the ITS5F and ITS4R universal primers. The following polymerase chain reaction (PCR) programme was used for amplification: initial denaturation at $94{ }^{\circ} \mathrm{C}$ for $3 \mathrm{~min}$, followed by 30 (bacterial) or 40 (fungal) cycles of $94{ }^{\circ} \mathrm{C}$ for $45 \mathrm{~s}, 52{ }^{\circ} \mathrm{C}$ for $45 \mathrm{~s}$, and $72{ }^{\circ} \mathrm{C}$ for $1 \mathrm{~min}$ (bacterial) or $1.5 \mathrm{~min}$ (fungal). A final step of $72{ }^{\circ} \mathrm{C}$ for 6 min was included. Samples were loaded on a $10 \%$ (bacterial) or $5 \%$ (fungal) denaturing gel and cluster analysis of gel images was performed using Phoretix software (TotalLab, UK). 
Table 1 Patient data for the paediatric patient cohort involved in the microbiome study

\begin{tabular}{|c|c|c|c|c|c|c|c|}
\hline ID no. & Age (years) & Sex & IV antibiotics ${ }^{\mathrm{a}}$ & PO antibiotics ${ }^{\mathrm{a}}$ & FEV $\%{ }^{\mathrm{b}}$ & Mutation & $\mathrm{BA}(\mu \mathrm{M})$ \\
\hline 1 & 17 & M & 28 & 56 & $90 \%$ & $\Delta \mathrm{F} 508 / \Delta \mathrm{F} 508$ & 0.34 \\
\hline 2 & 15 & $\mathrm{~F}$ & 28 & 14 & $85 \%$ & $\Delta \mathrm{F} 508 / \Delta \mathrm{F} 508$ & 0.50 \\
\hline 3 & 8 & M & 0 & 56 & $104 \%$ & $\Delta \mathrm{F} 508 / \Delta \mathrm{F} 508$ & 0.50 \\
\hline 4 & 11 & M & 30 & $\mathrm{CM}+56$ days $\mathrm{CP}$ & $85 \%$ & $\Delta \mathrm{F} 508 / \Delta \mathrm{F} 508$ & 0.16 \\
\hline 5 & 12 & M & 14 & & $97 \%$ & $\Delta \mathrm{F} 508 / \Delta \mathrm{F} 508$ & 0.28 \\
\hline 6 & 16 & M & 21 & $\mathrm{CM}+28$ days $\mathrm{CP}$ & $86 \%$ & $\Delta \mathrm{F} 508 / \Delta \mathrm{F} 508$ & 0.1 \\
\hline 7 & 16 & M & 14 & $\mathrm{CM}$ & $92 \%$ & $\Delta \mathrm{F} 508 / \Delta \mathrm{F} 508$ & 0.27 \\
\hline 8 & 9 & M & 42 & $\mathrm{CM}$ & $89 \%$ & $\Delta$ F508/G542 & 1.16 \\
\hline 9 & 14 & M & 14 & $\mathrm{CM}$ & $92 \%$ & $\Delta \mathrm{F} 508 / \Delta \mathrm{F} 508$ & 0.53 \\
\hline 10 & 16 & $\mathrm{~F}$ & 70 & $\mathrm{Ma}+\mathrm{PO} \mathrm{CP}$ & $52 \%$ & $\Delta \mathrm{F} 508 / \Delta \mathrm{F} 508$ & 0.11 \\
\hline 11 & 12 & $\mathrm{~F}$ & 0 & $\mathrm{CM}$ & $79 \%$ & $\Delta \mathrm{F} 508 / \mathrm{G} 551 \mathrm{D}$ & 0.55 \\
\hline 12 & 9 & M & 65 & CM. month on/off MT \& AM & $42 \%$ & $\Delta \mathrm{F} 508 / \Delta \mathrm{F} 508$ & 1.0 \\
\hline 13 & 14 & $\mathrm{~F}$ & SC IV antibiotics & $\mathrm{CM}$ or $\mathrm{CD}$ & $30 \%$ & $\Delta \mathrm{F} 508 / \Delta \mathrm{F} 508$ & 14.5 \\
\hline 14 & 9 & M & 14 & 42 days & $101 \%$ & G55ID/Glu56Lys & 1.22 \\
\hline 15 & 7 & $\mathrm{~F}$ & 42 & $\mathrm{CM}$ & $94 \%$ & $\Delta \mathrm{F} 508 / \Delta \mathrm{F} 508$ & 1.12 \\
\hline 16 & 13 & M & 0 & $\mathrm{CM}$ & $75 \%$ & $\Delta$ F508/G551D & 0.04 \\
\hline 17 & 13 & M & 36 & $\mathrm{CM}+\mathrm{PO}$ antibiotics & $90 \%$ & $\Delta \mathrm{F} 508 / \Delta \mathrm{F} 508$ & 0.11 \\
\hline $18^{\mathrm{c}}$ & 11 & M & 14 & $\mathrm{CM}$ & $118 \%$ & $\mathrm{G} 55 \mathrm{ID} / \Delta \mathrm{F} 508$ & 1.0 \\
\hline 19 & 7 & $\mathrm{~F}$ & 14 & $\mathrm{CM}$ & $91 \%$ & $\Delta \mathrm{F} 508 / \Delta \mathrm{F} 508$ & 0.20 \\
\hline 20 & 6 & M & 0 & 42 days & $94 \%$ & $\Delta \mathrm{F} 508^{\mathrm{d}}$ & 0.18 \\
\hline 21 & 19 & M & 28 & 100 days & $84 \%$ & $\Delta \mathrm{F} 508 / \Delta \mathrm{F} 508$ & $\mathrm{GOR}^{\mathrm{e}}$-ve \\
\hline 22 & 11 & M & 28 & 70 days & $91 \%$ & $\Delta \mathrm{F} 508 / \Delta \mathrm{F} 508$ & GOR -ve \\
\hline 23 & 15 & M & 28 & 0 & $96 \%$ & $\Delta \mathrm{F} 508 / \mathrm{G} 551 \mathrm{D}$ & GOR -ve \\
\hline 24 & 16 & M & 14 & 28 days & $72 \%$ & $\Delta \mathrm{F} 508 / \Delta \mathrm{F} 508$ & 0.6 \\
\hline 25 & 8 & $\mathrm{~F}$ & 49 & 42 days & $96 \%$ & $\Delta \mathrm{F} 508 / \Delta \mathrm{F} 508$ & $\mathrm{GOR}+\mathrm{ve}$ \\
\hline
\end{tabular}

$\mathrm{CD}$, doxycycline; $\mathrm{CM}$, chronic macrolide; PO, oral antibiotics; SC, semi-continuous

${ }^{\text {a }}$ Number of days in 2012

${ }^{\mathrm{b}}$ Predicted baseline

${ }^{\mathrm{c}}$ Patient commenced ivacaftor treatment

${ }^{\mathrm{d}}$ Heterozygote, second mutation not identified

${ }^{\text {e }}$ Symptom-based classification

\section{S rRNA pyrosequencing analysis}

DNA from Sputolysin-treated samples was quantified and standardised at a final concentration of $25 \mathrm{ng} / \mu \mathrm{l}$. Samples were subsequently sent for $16 \mathrm{~S}$ rRNA amplification and high-throughput sequencing using the Roche FLX Genome Sequencer in combination with Titanium Chemistry at DNAVision (Belgium). Detailed procedures are provided in Online Resource 1. Briefly, amplification of the V1-V3 region was achieved using the universal primers 518R 5'-ATTA CCGCGGCTGCTGG-3' and 27F 5'-AGAGTTTGATCCTG GCTCAG-3' [16-18]. Amplicons were gel-purified and concentrations for all samples were determined by the PicoGreen assay. A nested PCR approach was taken in light of the low target DNA abundance of the samples, consistent with previous reports $[19,20]$. Comparison of the biodiversity profiles from nested and single-step amplification on the same samples did not reveal any skew or distortion of the taxonomic distribution (data not shown). Between 5,476 and 18,290 raw sequence reads (Online Resource 2) were obtained from the nested amplification for each sputum sample (minimum read length of $430 \mathrm{bp}$ ), from which 3,435-11,671 passed QC analysis (Online Resource 3). Each sequence passing QC was assigned to a family by the Ribosomal Database Project (RDP) classifier (v 2.1) with confidence estimate (CE) $>80 \%$ [21]. A minimum of $97 \%$ was assigned at the phyla level, while more than $95 \%$ of filtered 454 sequences was successfully classified down to the genus level. Richness and biodiversity indices based on operational taxonomic units (OTUs) were extracted using the mothur software platform [22]. The Chaol index was used for richness estimation, related to the number of observed OTUs. Biodiversity related to how 
uniformly the sequences are spread into the different observed OTUs was estimated with the non-parametric Shannon formula. Both indices were evaluated at different distance unit cutoffs, to test different selectivities in the definition of OTUs.

\section{Statistical analysis}

All data were analysed using Prism version 5.0 (GraphPad, San Diego, CA, USA) for statistical significance. GraphPad StatMate version 2.00 was used to establish that the study was adequately powered. As microbiome samples typically exhibit non-normal distributions, both a non-parametric Mann-Whitney $U$-test $[95 \%$ confidence interval $(\mathrm{CI})$, one tailed] and an unpaired $t$-test with Welch correction were applied. Unless otherwise stated, the Welch corrected $t$-test is presented and indicates statistical relevance in both tests. A parametric Student's $t$-test of unequal variance was performed on the DGGE data. In all cases, differences $<0.05$ were considered statistically significant.

\section{Results}

DGGE analysis of bacterial and fungal diversity in the paediatric CF cohort

To address the hypothesis that bile aspiration significantly influences the microbiology of the CF lung, DGGE profiling was performed on a paediatric patient cohort from Cork

\section{a} 16S rRNA Bacterial Biodiversity

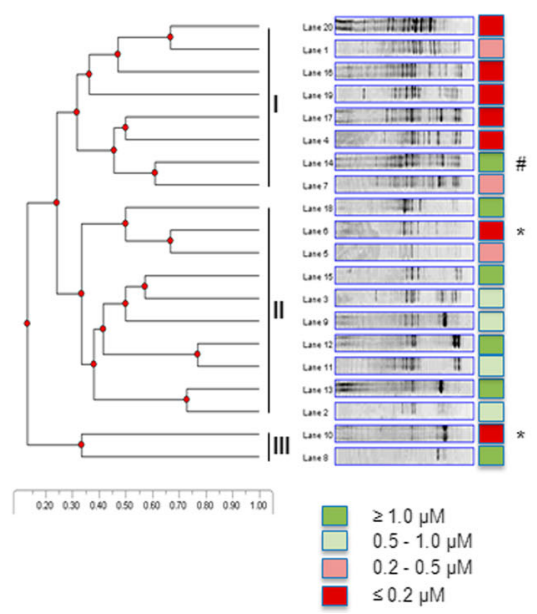

Fig. 1 Denaturing gradient gel electrophoresis (DGGE) analysis of bacterial and fungal biodiversity in aspirating and non-aspirating paediatric cystic fibrosis (CF) patients. a Patient samples separated into three distinct clades. The lane numbers refer to the patient ID for comparison of bacterial profiles. Lane $14^{\#}$ represents a patient that has only recently been diagnosed with $\mathrm{CF}$ and is an outlier to this analysis. Lanes $6^{*}$ and $10^{*}$ represent samples from patients that are symptomatic for gastro-
University Hospital, Ireland. Bacterial 16S rDNA profiles were initially analysed from sputum samples taken from nine patients and were correlated with the clinical classification of gastro-oesophageal reflux disease (GORD) status (Table 1 and Online Resource 4). A marked reduction in biodiversity was evident from those patients whose status was symptomatic for GORD compared to those who were asymptomatic. While this suggested that bile aspiration may, indeed, influence the biodiversity of the CF lung, there is a growing acceptance that bile aspiration may be asymptomatic and more accurate technologies are required to measure bile acids in the lungs. Therefore, in order to evaluate the occurrence and extent of bile aspiration in our paediatric CF cohort, a protocol for LCMS bile acid analysis in sputum was developed (Reen, F.J., Woods, D., Zhou, L. et al., manuscript in preparation). Additional sputum samples were obtained from the paediatric $\mathrm{CF}$ cohort $(n=25)$, from which bacterial and fungal biodiversity profiles were generated. Patients were classified as either bile aspirating or non-aspirating on the basis of LC-MS analysis on sputum (Table 1). DGGE profiles clustered on the basis of aspiration status with marked reductions in bacterial biodiversity observed in aspirating samples relative to non-aspirating samples (Fig. 1a). Cluster analysis of fungal biodiversity profiles was less clear (Fig. 1b), although the paediatric samples were limited for fungal colonisation, which is unsurprising given the age profile of the cohort (Table 1). Taken together, this analysis suggested that bile aspiration into the lungs of paediatric CF patients had a significant influence on the microbiology of the lung.

b
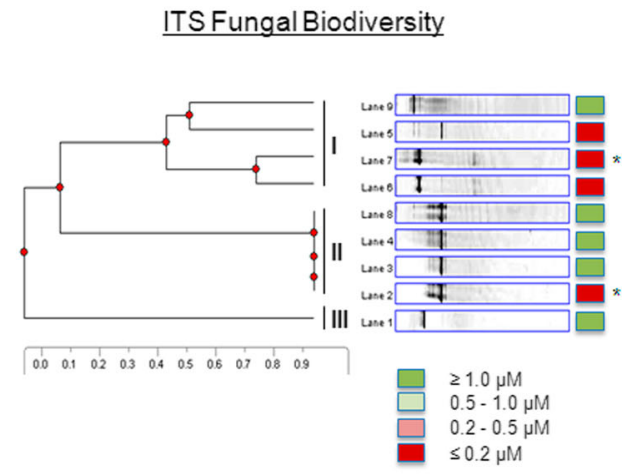

oesophageal reflux disease (GORD). Statistical analysis was performed by Student's $t$-test. b Fungal biodiversity profiles based on internally transcribed region (ITS) sequence variation. Lanes $7^{*}$ and $2^{*}$, respectively, represent the GORD-positive outliers described above. The lane numbers refer to the following patient ID numbers in parentheses: Lane 1 (8), Lane 2 (10), Lane 3 (15), Lane 4 (13), Lane 5 (16), Lane 6 (19), Lane 7 (6), Lane 8 (12), Lane 9 (18) 
Pyrosequencing biodiversity analysis of the paediatric $\mathrm{CF}$ microbiome: aspirating vs. non-aspirating

In order to characterise the influence of bile aspiration on the CF microbiome, 454 pyrosequencing (DNAVision, Belgium) was performed ( $n=10$, Online Resource 5). On the basis of the sputum bile acid profiling, five bile aspirating and fi non-bile aspirating samples, matched for age and antibiotic profile, were selected. Indeed, analysis of the clinical and demographic data for bile aspirating and non-aspirating patients revealed no significant difference in FEV\%, age or IV antibiotics between both cohorts (Online Resource 6). However, it should be noted that two of the lowest FEV\% were recorded for aspirating patients, while one aspirating patient had commenced ivacaftor treatment (Table 1). The biodiversity index of each sample was calculated using the non-parametric Shannon algorithm and the bile aspirating samples were found to have a significantly lower diversity index $(p=0.0079)$ than the non-bile aspirating samples (Fig. 2a). This was further borne out by the Chaol richness index, which was also statistically significantly reduced (Mann-Whitney $p=0.0079$ ) in the bile aspirating samples (Fig. 2b). This reduction in the biodiversity

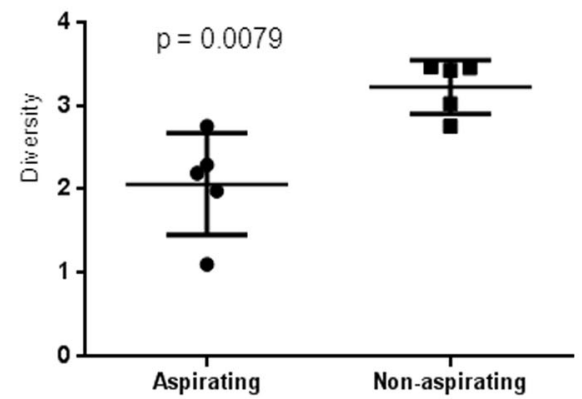

C

Highest Relative Abundance (Family)

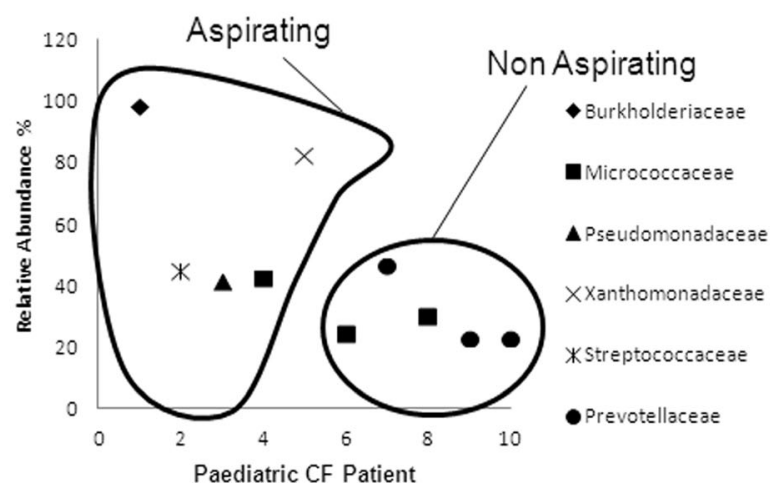

Fig. 2 Microbiome analysis of bile aspirating and non-aspirating paediatric patients. a Diversity (non-parametric Shannon) and (b) richness (Chao1) indices from the pyrosequencing dataset. The figures are representative of five patient samples for both aspirating and non-aspirating index is comparable to previous reports from adult $\mathrm{CF}$ patients when compared with healthy non-CF patients $[9,11,23]$. In addition to the reduced biodiversity, another distinctive feature of the aspirating patient samples was the presence of dominant proteobacterial genera, while non-aspirating patients were characterised by the abundance of genera more associated with healthy non-CF lungs (Fig. 2c, d) [9].

Phylum, family and genus level analysis: impact of bile aspiration

The analysis of biodiversity at the phylum level revealed a significantly lower relative abundance of Bacteroidetes $(p=0.0135)$ and Fusobacteriaceae $(p=0.0291)$ in bile aspirating patients compared to non-aspirating, with the latter phylum being almost entirely absent (Fig. 3a and Online Resource 5). The ratio of Firmicutes to Bacteroidetes, previously shown to be a marker for the pervasive CF microbiome, was 5.13 $( \pm 4.14)$ in aspirating patients and $1.11( \pm 0.51)$ in nonaspirating patients. The analysis of family level diversity (Fig. 3b and Online Resource 5) revealed lower relative abundance of Veillonellaceae $(p=0.0173)$, Fusobacteriaceae

b

Chao Index $(0.03)$

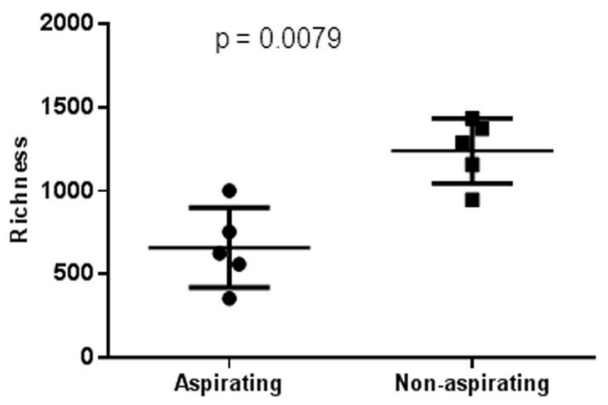

d

\section{Prevotellaceae, Veillonaceae and Pasteurellaceae}

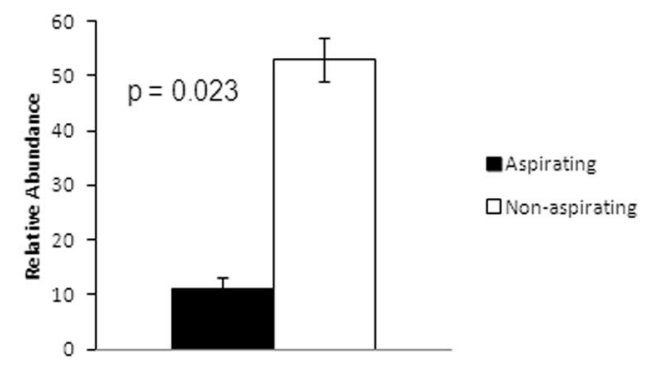

[Mann-Whitney $U$-test $(p<0.05)]$. c Family with the highest relative abundance in each patient sample. d Combined relative abundance of Prevotellaceae, Veillonellaceae and Pasteurellaceae in non-aspirating patients relative to aspirating patients [Student's $t$-test $(p<0.05)$ ] 


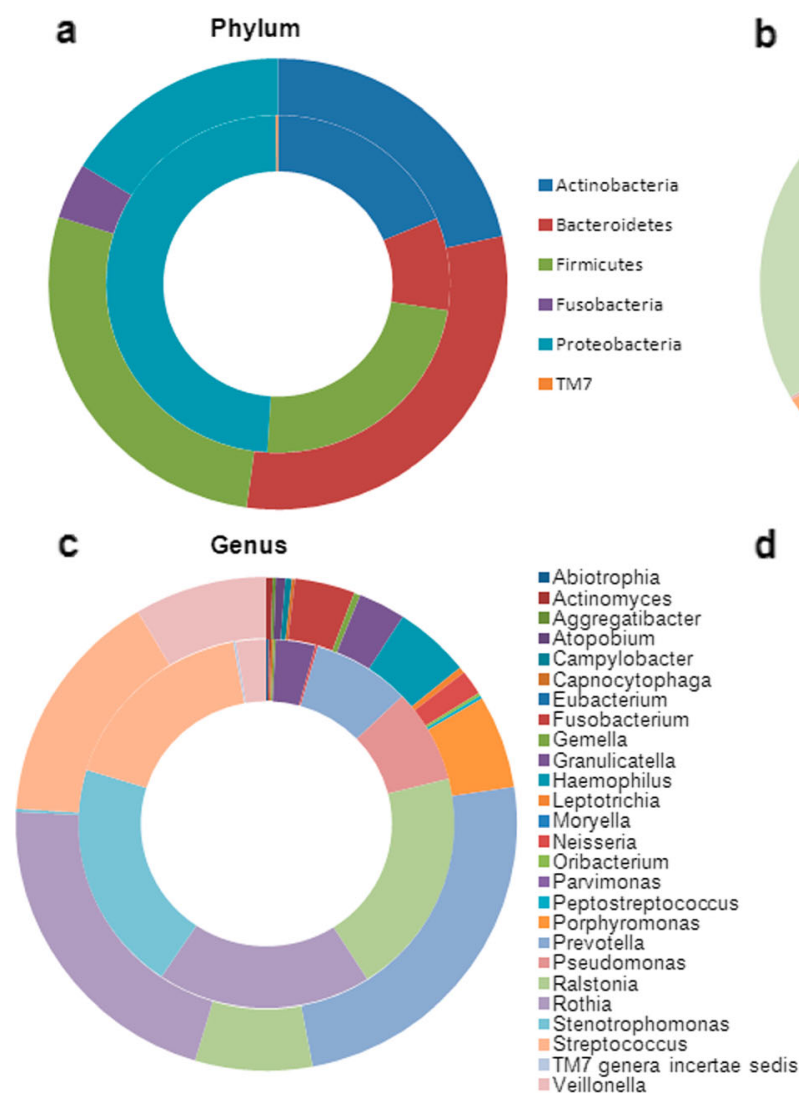

Fig. 3 a Phylum, b family and $\mathbf{c}$ genus level analysis of the paediatric microbiome in aspirating and non-aspirating patients. In all cases, aspirating samples are represented by the inner circle, while non-aspirating samples are represented by the outer circle. Relative abundances $\geq 1 \%$ are

( $p=0.04)$ and Prevotellaceae $(p=0.0422)$ in aspirating samples. Furthermore, Pasteurellaceae were significantly less prevalent in aspirating patients $(p<0.05)$.

Genus level analysis (Fig. 3c and Online Resource 5) revealed the prevalence of dominant proteobacterial species in $3 / 5$ of the bile aspirating samples. These genera (Ralstonia, Pseudomonas and Stenotrophomonas) accounted for 45-98\% of the total microbiome in these patients. Additional bile aspirating patients were dominated by Streptococcus (45\%) and Rothia (43\%). In contrast, the non-bile aspirating patients contained significantly higher biodiversity, even where Prevotella was present at $>40 \%$. Bile aspirating samples were notable for the almost exclusive absence (with the exception of patient $5,0.1 \%$ relative abundance) of Haemophilus, which was present in 4/5 non-aspirating samples. Furthermore, aspirating samples were also characterised by a lower relative abundance of Veillonella $(p=0.0123)$, Prevotella $(p=$ $0.0462)$, Fusobacteria $(p=0.0391)$ and Leptotrichia ( $p=$ 0.0426 ) in these patients. Taken together, these data indicate a strong correlation between the aspiration of bile acids and the prevalence of $\mathrm{CF}$-associated pathogens in the paediatric lung.

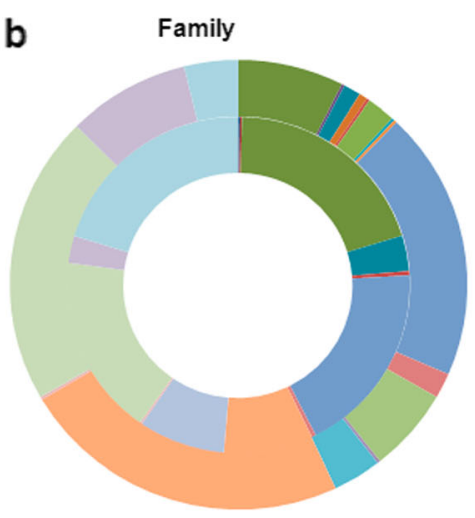

d
- Actinomycetaceae - Burococcaceae Campylobacteraceae - Carnobacteriaceae Coriobacteriaceae - Eubacteriaceae Flavobacteriaceae Fusobacteriaceae Incertae Sedis XI Lachnospiraceae Leptotrichiaceae Micrococcaceae Neisseriaceae Pasteurellaceae Prevotellaceae Pseudomonadaceae Staphylococcaceae Streptococcacea - Veillonellaceae Xanthomonadaceae Peptostreptococcaceae Porphyromonadaceae

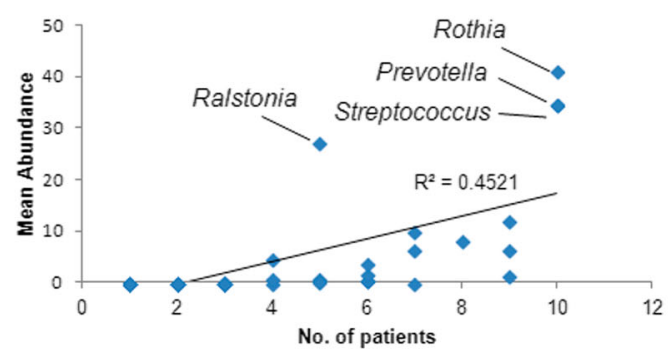

presented. $\mathbf{d}$ The relative abundance of genera was not linear relative to the patient number $\left(R^{2}=0.4521\right)$, with Ralstonia, Rothia, Streptococcus and Prevotella being over-represented compared to other genera

\section{Discussion}

Several recent studies have investigated the lung microbiome in a broad spectrum of respiratory diseases. Despite differences in experimental design, e.g. sequencing technology and specimen type, there is strong concordance among the reports $[9,10,20,24-26]$. Contrary to the perceived sterility of the healthy lung, microbial communities that may contribute to disease have been identified [9], while respiratory conditions such as CF, chronic obstructive pulmonary disease (COPD) and asthma were found to have distinct lung microbial profiles, both from each other and from the healthy lung $[9,10$, 27]. A pattern emerging from these reports is the complexity of the microbial communities that exist in the different infection niches, leading to a re-evaluation of organisms that have traditionally been regarded as commensals. There is growing evidence that the diversity of these profiles may play a previously unforseen role in disease progression, in tandem with the well-studied pathogens such as $P$. aeruginosa, $H$. influenzae and S. aureus $[9,10,13,14]$.

Having established the profile of bile aspirating and nonaspirating patients within our $\mathrm{CF}$ cohort, the microbiome from 
these distinct patient groups was analysed. The suitability of sputum for this research has previously been established by several independent studies [9, 10, 28], which have shown that it reflects a microbiome distinct from the oropharyngeal tract and consistent with that of explanted lungs. Furthermore, recent bronchoalveolar lavage (BAL) data from Aseeri and colleagues confirms the presence of bile acids in the lower respiratory tract [1]. A key characteristic of the previously established CF microbiome is the markedly reduced biodiversity compared to non-CF samples, often correlating with the emergence of dominant pathogenic species within the lung. Our analysis shows that the bile aspirating patients exhibit markedly reduced biodiversity compared to non-aspirating patients, mirroring the outcome of the recent $\mathrm{CF}$ vs. non-CF microbiome studies (Fig. 2). Furthermore, in three of the aspirating samples, the reduced biodiversity correlated with the presence of a single dominant proteobacterial genus. This is particularly interesting and is consistent with our hypothesis that bile aspiration triggers the emergence of chronicbehaving dominant organisms that ultimately cause the chronic destruction of the lung [8].

Consistent with previous microbiome studies, the microbial profiles were quite diverse within the CF cohort [9]. Microbial families that were found to be more prevalent among CF patients, e.g. Pseudomonadaceae and Aerococcaceae $[9,13]$, were only present at relative abundances $>1.0 \%$ in bile aspirating patients. Conversely, Prevotellaceae, Veillonellaceae, Fusobacteriaceae and Leptotrichiaceae, which are more prevalent in healthy non-CF patients $[9$, 13], were significantly more abundant in non-aspirating patients. The apparent suppression of genera that require anaerobic conditions for growth, such as Veillonella and Prevotella, is highly significant, given that previous studies have shown that almost half of the cultured CF airway microbial community in adult sputum is composed of obligate anaerobes [13]. Furthermore, several studies have shown that the administration of antibiotic regimens targeting aerobic pathogens does not appear to significantly alter the anaerobic microflora in CF patients $[29,30]$. It is interesting, therefore, to speculate that the reduction of anaerobic bacteria in aspirating patients may arise as a consequence of the emergence of dominant proteobacterial pathogens, particularly in light of our recent finding that bile causes respiratory pathogens to adopt a chronic lifestyle [8]. Alternatively, anaerobic bacteria may be more sensitive to bile acids, and this will need to be followed up by future in vitro studies.

The possibility that antibiotic treatment is responsible for the lower biodiversity in aspirating patients was considered but is not supported by the evidence. The antibiotic regimens of all ten patients included in this study were comparable, although the non-aspirating samples underwent, on average, a shorter period of IV antibiotic treatment (Table 1 and Online Resource 6). Furthermore, given that most $\mathrm{CF}$ patients undergo prolonged antibiotic treatments, the administration of additional antibiotics during exacerbation are not likely to cause significant changes in the microbial community structure [9]. Also, importantly, the consistency of the replicates included in the study, which were taken at least 2 months apart (Online Resource 4 and Fig. 1), strongly supports the hypothesis that bile aspiration is a major influence on microbial biodiversity in the $\mathrm{CF}$ lung.

This study provides strong evidence that bile aspiration is a major factor in shaping the CF microbiome, from an early stage in paediatric patients. While consistent with the influence of bile on the chronic behaviour of respiratory pathogens [8], further studies will be required on a larger patient cohort to establish whether the association between bile aspiration and reduced microbial biodiversity is causative or correlative. Further analysis of co-morbidities associated with GORD, such as gastrointestinal disease and chronic cough, will be undertaken, while the integration of BAL samples into the analysis will provide additional confirmation of the response in the lower respiratory tract. It is important to note that, while the current study focused on CF patients, the problems associated with bile aspiration are far more widespread in respiratory disease. The aspiration of bile acids has been confirmed in sputum and BAL samples from patients suffering from a range of other respiratory diseases, including COPD and asthma, and following lung transplantation [31, 32]. Studies have also found a significant correlation between GOR and $P$. aeruginosa infection [33,34], as well as reduced lung function in $\mathrm{CF}$ and other respiratory patients following lung transplantation [35, 36]. Current treatment strategies for the management of GOR may not be effective in preventing the subsequent influence on the respiratory microbiome. The most effective solution for the prevention of GOR and bile aspiration is surgery, specifically Nissen fundoplication, although the high risks associated with this approach highlight the need for alternatives. Therefore, alternative innovative therapeutic strategies will be required in order to target the link between this key host trigger and the onset of chronic infection. This highlights the need for a largescale study of bile aspiration in paediatric patients with $\mathrm{CF}$ and other respiratory conditions, with the specific aim of characterising the influence of bile aspiration on the microbiology of the lung and elucidating the molecular mechanisms underpinning changes in the microbial community structure. 
Acknowledgements The authors acknowledge the excellent technical assistance provided by Pat Higgins at UCC and the physiotherapy staff and nursing staff in the Paediatric Cystic Fibrosis Clinic at Cork University Hospital, particularly Pat Shanahan, Deirdre O'Donovan and Rose Jennings. The authors also thank Anthony Fitzgerald, UCC, for the helpful discussions on the statistical analysis. In addition, the contribution of Audrey Dearing and Ailish O'Keeffe to the DGGE analysis is acknowledged. This research was supported, in part, by grants awarded to FOG by the Science Foundation of Ireland (SSPC2 12/RC/2275, 13TIDA-B2625, 07/IN.1/B948, 12/TIDA/B2411, 12/TIDA/B2405,09/ RFP/BMT 2350); the Department of Agriculture, Fisheries and Food (DAFF11/F/009 MabS, FIRM/RSF/CoFoRD, FIRM 08/RDC/629); the Environmental Protection Agency (EPA 2008-PhD/S-2), the Irish Research Council for Science, Engineering and Technology (PD/2011/2414; RS/2010/2413), the European Commission (FP7-PEOPLE-2013-ITN, 607786; OCEAN2012, 287589; FP7-KBBE-2012-6, CP-TP 311975; FP7-KBBE-2012-6, CP-TP-312184; Marie Curie 256596) and the Marine Institute (Beaufort award C2CRA 2007/082); Teagasc (Walsh Fellowship 2013) and the Health Research Board (HRA/2009/146). JDG and DF thank the Science Foundation Ireland (grant number 08/SRC/ B1412) for research funding of the Irish Separation Science Cluster (ISSC) under the Strategic Research Cluster programme. GPM acknowledges support by the Science Foundation Ireland under grant nos. SFI/12/ IP/1315, SFI/09/RFP/CHS2353 and SFI/12/TIDA/B2405.

Conflict of interest The authors state that they have no conflict of interest.

Open Access This article is distributed under the terms of the Creative Commons Attribution License which permits any use, distribution, and reproduction in any medium, provided the original author(s) and the source are credited.

\section{References}

1. Aseeri A, Brodlie M, Lordan J, Corris P, Pearson J, Ward C, Manning $\mathrm{N}$ (2012) Bile acids are present in the lower airways of people with cystic fibrosis. Am J Respir Crit Care Med 185(4):463

2. Blondeau K, Pauwels A, Dupont LJ, Mertens V, Proesmans M, Orel R, Brecelj J, López-Alonso M, Moya M, Malfroot A, De Wachter E, Vandenplas Y, Hauser B, Sifrim D (2010) Characteristics of gastroesophageal reflux and potential risk of gastric content aspiration in children with cystic fibrosis. J Pediatr Gastroenterol Nutr 50(2):161166

3. D'Ovidio F, Mura M, Tsang M, Waddell TK, Hutcheon MA, Singer LG, Hadjiliadis D, Chaparro C, Gutierrez C, Pierre A, Darling G, Liu M, Keshavjee S (2005) Bile acid aspiration and the development of bronchiolitis obliterans after lung transplantation. J Thorac Cardiovasc Surg 129(5):1144-1152

4. Pauwels A, Decraene A, Blondeau K, Mertens V, Farre R, Proesmans M, Van Bleyenbergh P, Sifrim D, Dupont LJ (2012) Bile acids in sputum and increased airway inflammation in patients with cystic fibrosis. Chest 141(6):1568-1574

5. D'Ovidio F, Singer LG, Hadjiliadis D, Pierre A, Waddell TK, de Perrot M, Hutcheon M, Miller L, Darling G, Keshavjee S (2005) Prevalence of gastroesophageal reflux in end-stage lung disease candidates for lung transplant. Ann Thorac Surg 80(4):1254-1260

6. Navarro J, Rainisio M, Harms HK, Hodson ME, Koch C, Mastella G, Strandvik B, McKenzie SG (2001) Factors associated with poor pulmonary function: cross-sectional analysis of data from the
ERCF. European Epidemiologic Registry of Cystic Fibrosis. Eur Respir J 18(2):298-305

7. Stringer DA, Sprigg A, Juodis E, Corey M, Daneman A, Levison HJ, Durie PR (1988) The association of cystic fibrosis, gastroesophageal reflux, and reduced pulmonary function. Can Assoc Radiol J 39(2): $100-102$

8. Reen FJ, Woods DF, Mooij MJ, Adams C, O'Gara F (2012) Respiratory pathogens adopt a chronic lifestyle in response to bile. PLoS One 7(9):e45978

9. Blainey PC, Milla CE, Cornfield DN, Quake SR (2012) Quantitative analysis of the human airway microbial ecology reveals a pervasive signature for cystic fibrosis. Sci Transl Med 4(153):153ra130

10. Cox MJ, Allgaier M, Taylor B, Baek MS, Huang YJ, Daly RA, Karaoz U, Andersen GL, Brown R, Fujimura KE, Wu B, Tran D, Koff J, Kleinhenz ME, Nielson D, Brodie EL, Lynch SV (2010) Airway microbiota and pathogen abundance in age-stratified cystic fibrosis patients. PLoS One 5(6):e11044

11. Harris JK, De Groote MA, Sagel SD, Zemanick ET, Kapsner R, Penvari C, Kaess H, Deterding RR, Accurso FJ, Pace NR (2007) Molecular identification of bacteria in bronchoalveolar lavage fluid from children with cystic fibrosis. Proc Natl Acad Sci U S A 104(51): 20529-20533

12. Harrison F (2007) Microbial ecology of the cystic fibrosis lung. Microbiology 153(Pt 4):917-923

13. Sibley CD, Grinwis ME, Field TR, Eshaghurshan CS, Faria MM, Dowd SE, Parkins MD, Rabin HR, Surette MG (2011) Culture enriched molecular profiling of the cystic fibrosis airway microbiome. PLoS One 6(7):e22702

14. Sibley CD, Surette MG (2011) The polymicrobial nature of airway infections in cystic fibrosis: Cangene Gold Medal Lecture. Can J Microbiol 57(2):69-77

15. Tagliacozzi D, Mozzi AF, Casetta B, Bertucci P, Bernardini S, Di Ilio C, Urbani A, Federici G (2003) Quantitative analysis of bile acids in human plasma by liquid chromatography-electrospray tandem mass spectrometry: a simple and rapid one-step method. Clin Chem Lab Med 41(12):1633-1641

16. Lane DJ (1991) 16S/23S rRNA sequencing. In: Stackebrandt E, Goodfellow M (eds) Nucleic acid techniques in bacterial systematics. Wiley, Chichester, pp 115-175

17. Muyzer G, de Waal EC, Uitterlinden AG (1993) Profiling of complex microbial populations by denaturing gradient gel electrophoresis analysis of polymerase chain reaction-amplified genes coding for 16S rRNA. Appl Environ Microbiol 59(3):695-700

18. Wu GD, Lewis JD, Hoffmann C, Chen YY, Knight R, Bittinger K, Hwang J, Chen J, Berkowsky R, Nessel L, Li H, Bushman FD (2010) Sampling and pyrosequencing methods for characterizing bacterial communities in the human gut using $16 \mathrm{~S}$ sequence tags. BMC Microbiol 10:206

19. Erb-Downward JR, Huffnagle GB, Martinez FJ (2012) The microbiota in respiratory disease. Am J Respir Crit Care Med 185(10):10371038

20. Sze MA, Dimitriu PA, Hayashi S, Elliott WM, McDonough JE, Gosselink JV, Cooper J, Sin DD, Mohn WW, Hogg JC (2012) The lung tissue microbiome in chronic obstructive pulmonary disease. Am J Respir Crit Care Med 185(10):1073-1080

21. Wang Q, Garrity GM, Tiedje JM, Cole JR (2007) Naive Bayesian classifier for rapid assignment of rRNA sequences into the new bacterial taxonomy. Appl Environ Microbiol 73(16):5261-5267

22. Schloss PD, Westcott SL, Ryabin T, Hall JR, Hartmann M, Hollister EB, Lesniewski RA, Oakley BB, Parks DH, Robinson CJ, Sahl JW, Stres B, Thallinger GG, Van Horn DJ, Weber CF (2009) Introducing mothur: open-source, platform-independent, community-supported software for describing and comparing microbial communities. Appl Environ Microbiol 75(23):7537-7541 
23. Rogers GB, Carroll MP, Serisier DJ, Hockey PM, Kehagia V, Jones GR, Bruce KD (2005) Bacterial activity in cystic fibrosis lung infections. Respir Res 6:49

24. Erb-Downward JR, Thompson DL, Han MK, Freeman CM, McCloskey L, Schmidt LA, Young VB, Toews GB, Curtis JL, Sundaram B, Martinez FJ, Huffnagle GB (2011) Analysis of the lung microbiome in the "healthy" smoker and in COPD. PLoS One 6(2): e16384

25. Hilty M, Burke C, Pedro H, Cardenas P, Bush A, Bossley C, Davies J, Ervine A, Poulter L, Pachter L, Moffatt MF, Cookson WO (2010) Disordered microbial communities in asthmatic airways. PLoS One 5(1): $\mathrm{e} 8578$

26. Huang YJ, Kim E, Cox MJ, Brodie EL, Brown R, Wiener-Kronish JP, Lynch SV (2010) A persistent and diverse airway microbiota present during chronic obstructive pulmonary disease exacerbations. OMICS 14(1):9-59

27. Huang YJ (2013) Asthma microbiome studies and the potential for new therapeutic strategies. Curr Allergy Asthma Rep 13(5):453-461

28. Blau H, Linnane B, Carzino R, Tannenbaum EL, Skoric B, Robinson PJ, Robertson C, Ranganathan SC (2014) Induced sputum compared to bronchoalveolar lavage in young, non-expectorating cystic fibrosis children. J Cyst Fibros 13(1):106-110

29. Tunney MM, Klem ER, Fodor AA, Gilpin DF, Moriarty TF, McGrath SJ, Muhlebach MS, Boucher RC, Cardwell C, Doering G, Elborn JS, Wolfgang MC (2011) Use of culture and molecular analysis to determine the effect of antibiotic treatment on microbial community diversity and abundance during exacerbation in patients with cystic fibrosis. Thorax 66(7):579-584
30. Worlitzsch D, Rintelen C, Böhm K, Wollschläger B, Merkel N, Borneff-Lipp M, Döring G (2009) Antibiotic-resistant obligate anaerobes during exacerbations of cystic fibrosis patients. Clin Microbiol Infect 15(5):454-460

31. Pauwels A, Decraene A, Blondeau K, Mertens V, Farre R, Proesmans M, Van Bleyenbergh P, Sifrim D, Dupont LJ (2012) Bile acids in sputum and increased airway inflammation in patients with cystic fibrosis. Chest 141(6):1568-1574

32. Wu YC, Hsu PK, Su KC, Liu LY, Tsai CC, Tsai SH, Hsu WH, Lee YC, Perng DW (2009) Bile acid aspiration in suspected ventilatorassociated pneumonia. Chest 136(1):118-124

33. Palm K, Sawicki G, Rosen R (2012) The impact of reflux burden on Pseudomonas positivity in children with cystic fibrosis. Pediatr Pulmonol 47(6):582-587

34. van der Doef HP, Arets HG, Froeling SP, Westers P, Houwen RH (2009) Gastric acid inhibition for fat malabsorption or gastroesophageal reflux disease in cystic fibrosis: longitudinal effect on bacterial colonization and pulmonary function. $\mathrm{J}$ Pediatr 155(5):629-633

35. Vos R, Blondeau K, Vanaudenaerde BM, Mertens V, Van Raemdonck DE, Sifrim D, Dupont LJ, Verleden GM (2008) Airway colonization and gastric aspiration after lung transplantation: do birds of a feather flock together? J Heart Lung Transplant 27(8): 843-849

36. Vos R, Vanaudenaerde BM, Dupont LJ, Van Raemdonck DE, Verleden GM (2007) Transient airway colonization is associated with airway inflammation after lung transplantation. Am J Transplant 7(5):1278-1287 